\title{
The effect of model spatial resolution on Secondary Organic Aerosol predictions: a case study at Whistler, BC, Canada
}

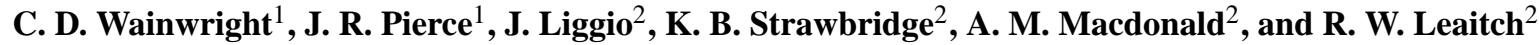 \\ ${ }^{1}$ Department of Physics and Atmospheric Science, Dalhousie University, Halifax, NS, Canada \\ ${ }^{2}$ Environment Canada, Toronto, Ontario, Canada
}

Correspondence to: J. R. Pierce (jeffrey.robert.pierce@gmail.com)

Received: 28 May 2012 - Published in Atmos. Chem. Phys. Discuss.: 28 June 2012

Revised: 24 September 2012 - Accepted: 9 October 2012 - Published: 20 November 2012

\begin{abstract}
A large fraction of submicron aerosol mass throughout the continental boundary layer consists of secondary organic aerosol (SOA) mass. As such, the ability of chemical transport models to accurately predict continental boundary layer aerosol greatly depends on their ability to predict SOA. Although there has been much recent effort to better describe SOA formation mechanisms in models, little attention has been paid to the effects of model spatial resolution on SOA predictions. The Whistler Aerosol and Cloud Study (WACS 2010), held between 22 June and 28 July 2010 and conducted at Whistler, BC, Canada provides a unique data set for testing simulated SOA predictions. The study consisted of intensive measurements of atmospheric trace gases and particles at several locations strongly influenced by biogenic sources in the region. We test the ability of the global chemical transport model GEOS-Chem to predict the aerosol concentrations during this event and throughout the campaign. Simulations were performed using three different resolutions of the model: $4^{\circ} \times 5^{\circ}, 2^{\circ} \times 2.5^{\circ}$ and $0.5^{\circ} \times 0.667^{\circ}$. Predictions of organic aerosol concentrations at Whistler were greatly dependent on the resolution; the $4^{\circ} \times 5^{\circ}$ version of the model significantly under predicts organic aerosol, while the $2^{\circ} \times 2.5^{\circ}$ and $0.5^{\circ} \times 0.667^{\circ}$ versions are much more closely correlated with measurements. In addition, we performed a comparison between the 3 versions of the model across North America. Comparison simulations were run for both a summer case (July) and Winter case (January). For the summer case, $0.5^{\circ} \times 0.667^{\circ}$ simulations predicted on average $19 \%$ more SOA than $2^{\circ} \times 2.5^{\circ}$ and $32 \%$ more than $4^{\circ} \times 5^{\circ}$. For the winter case, the $0.5^{\circ} \times 0.667^{\circ}$ simulations predicted $8 \%$ more SOA than the $2^{\circ} \times 2.5^{\circ}$ and $23 \%$ more than the $4^{\circ} \times 5^{\circ}$. This increase in SOA with reso-
\end{abstract}

lution is largely due to sub-grid variability of organic aerosol (OA) that leads to an increase in the partitioning of secondary organic matter to the aerosol phase at higher resolutions. SOA concentrations were further increased because the shift of secondary organic gases to SOA at higher resolutions increased the lifetime of secondary organic matter (secondary organic gases have a shorter deposition lifetime than SOA in the model). SOA precursor emissions also have smaller, but non-negligible, changes with resolution due to non-linear inputs to the MEGAN biogenic emissions scheme. These results suggest that a portion of the traditional under-prediction of SOA by global models may be due to the effects of coarse grid resolution.

\section{Introduction}

Atmospheric aerosols directly and indirectly affect the radiative balance and climate of the Earth. The direct effect is the scattering and absorption of solar radiation by aerosols in the atmosphere. The indirect effect is the influence of aerosols on cloud droplet number concentrations, which affects cloud albedo (Twomey, 1974) and potentially precipitation and cloud lifetime (Albrect, 1989). The magnitude of the combined uncertainties associated with these aerosol forcings is similar to the magnitude of the relatively well understood forcing from changes in $\mathrm{CO}_{2}$ concentrations (IPCC, 2007). These uncertainties in aerosol forcing are driven in part by uncertainties in how the concentration, size and composition of aerosols have changed due to human influence.

Aerosol mass can be produced by direct emission into the atmosphere (primary aerosols) or formed by physical 
and chemical processes within the atmosphere (secondary aerosols). Examples of primary aerosols include soot, sea salt and dust. Secondary aerosols are produced by atmospheric gases reacting in the gas or aqueous phases to form low-volatility products that increase aerosol mass. Primary and secondary aerosols have both natural and anthropogenic sources.

Between $20-90 \%$ of submicron aerosol mass throughout the continental boundary layer consists of organic aerosol mass (Jimenez et al., 2009). A significant fraction of this mass is thought to be secondary organic aerosol (SOA) that is formed in the atmosphere. SOA is split between biogenic and anthropogenic sources. Spracklen et al. (2011) showed that there are significant uncertainties associated with modeling boundary layer organic aerosol concentrations. Biogenic SOA is a major contributor to boundary layer SOA and is thus important to understand for modeling purposes. This biogenic SOA is formed in the atmosphere when volatile organic compounds (VOCs) released by plants, trees and other vegetation are oxidized in the atmosphere by $\mathrm{O}_{3}$, $\mathrm{NO}_{3}$, and $\mathrm{OH}$ (or oxidants in the condensed phase) to form low-volatility or semi-volatile products that partition to the aerosol phase. Anthropogenic SOA is formed through similar processes involving emission and reaction of VOCs and other chemicals of anthropogenic origin. The total amount of SOA formed in the atmosphere is highly uncertain and estimates published in the literature range from $12 \mathrm{Tg} \mathrm{yr}^{-1}$ (Kanakidou et al., 2005) to $1640 \mathrm{Tg} \mathrm{yr}^{-1}$ (Goldstein and Galbally, 2007). In addition, SOA has been found to strongly influence CCN formation and growth due to condensable organics growing freshly nucleated particles (Brock et al., 2011; Pierce et al., 2011; Riipinen et al., 2011). Organic aerosols can also affect the hygroscopicity of aerosol particles in the atmosphere, which is relevant to the subsequent CCN activity of the aerosol (Petters and Kreidenweis, 2007). Given that SOA contributes strongly to submicron aerosol mass and $\mathrm{CCN}$ concentrations, it is relevant to both the direct and indirect effects. Thus, if we are to accurately predict aerosol properties and their effects on air quality and climate, it is important that we understand the physical processes that shape SOA.

There has been much recent effort in better describing SOA formation mechanisms in models (e.g. Carlton et al., 2010; Kim et al., 2011; Lane et al., 2008; Lin et al., 2012); however, little attention has been paid to the role of model spatial resolution on SOA prediction. In global models, horizontal spatial resolution is often on the order of 500 kilometers (e.g. Pierce and Adams, 2009) and is usually no smaller than 200 kilometers (e.g. van Donkleear et al., 2010). Regional models generally have resolutions on the order of $10 \mathrm{~s}$ of kilometers (e.g. Lane et al., 2008; Carlton et al., 2010), but high-resolution model versions can have resolutions as low as $2.5 \mathrm{~km}$ (e.g. Stroud et al., 2011). Stroud et al. (2011) explored the effects of spatial resolution on SOA predictions in a regional model of a populated area in southern
Ontario, Canada. They found that when higher spatial resolutions were used, the predicted SOA production rates and subsequent temporal correlation were found to be more accurate. In addition, the predicted concentrations of SOA were generally higher at higher resolution. These results provide evidence that spatial resolution can affect SOA predictions in models and motivated us to explore similar ideas using a global model and other locations.

In this paper, we will evaluate how SOA predictions in the chemical transport model, GEOS-Chem, depend on grid resolution. Model simulations were performed at $4^{\circ} \times 5^{\circ}$, $2^{\circ} \times 2.5^{\circ}$ and $0.5^{\circ} \times 0.667^{\circ}$ resolutions (corresponding gridbox horizontal length scales around 400, 200 and $50 \mathrm{~km}$, respectively). The goals of this paper are two-fold:

1. We will evaluate the model predictions at the three resolutions using measurements done during the Whistler Aerosol and Cloud Study (WACS 2010) in July 2010. Whistler, BC, Canada is a particularly interesting location to study how model SOA predictions depend on model resolution. Though Whistler is located in a relatively remote mountain region, at large model horizontal resolutions (e.g. $4^{\circ} \times 5^{\circ}$ ) Whistler is in the same grid box as the city of Vancouver and the Pacific Ocean (Fig. 1). Thus at the coarsest resolutions, the Whistler grid-box will contain a mixture of marine, urban and remote continental influences and likely will not capture the SOA behavior of any of these locations properly.

2. We will determine how SOA predictions depend on model resolution throughout all of North America and examine the reasons for the dependence of SOA predictions on model resolution. Changes in SOA may be caused by changes in precursor emissions (which in GEOS-Chem depend non-linearly on surface properties and meteorology), gas-aerosol partitioning and the lifetime of organic matter, which all change with grid resolution.

In Sect. 2 of this paper, we discuss the instrumentation of the WACS 2010 campaign and the details of the GEOSChem model. In Sect. 3, we compare the model with the WACS 2010 observations. In addition, we compare SOA concentrations across North America and determine how the concentrations are affected by model resolution. The conclusions are given in Sect. 4.

\section{Methods}

\subsection{WACS 2010 instrumentation}

The WACS 2010 campaign took place in Whistler, BC, Canada between 22 June and 28 July 2010. Details of the meteorology and an overview of the main findings of the study are discussed in Macdonald et al. (2012). Three measurement sites were located on and around Whistler Mountain. 


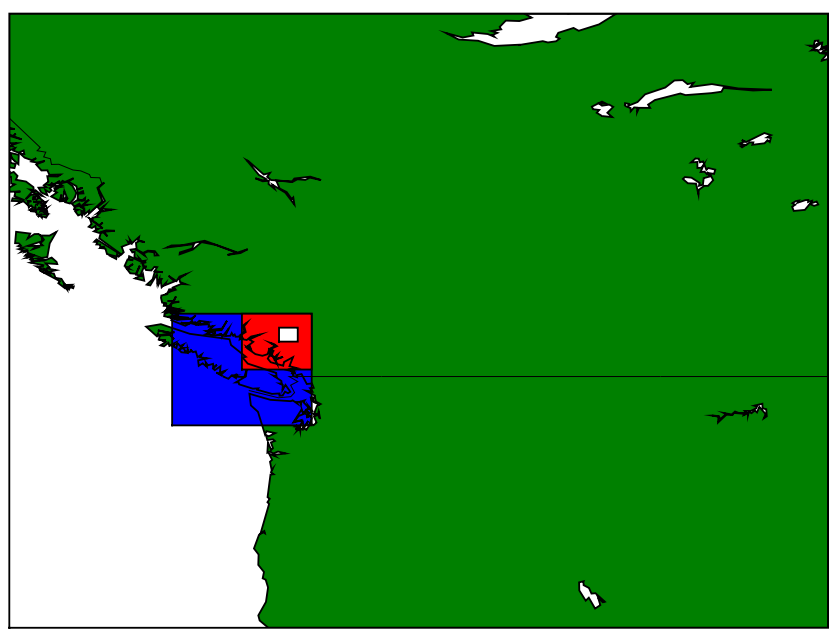

Fig. 1. A map showing the grid box that contains Whistler, BC, Canada for the $4^{\circ} \times 5^{\circ}$ (blue), $2^{\circ} \times 2.5^{\circ}$ (red) and $0.5^{\circ} \times 0.667^{\circ}$ (white) resolutions.

The first site was the Raven's Nest (a restaurant during ski season) at $1300 \mathrm{~m}$ a.s.l. and located roughly half way up the side of the mountain; the second site was on the peak of the mountain at $2200 \mathrm{~m}$ above sea level; and the third site was a measurement site used for Lidar, located just outside the Whistler village at the base of the mountain at $665 \mathrm{~m}$ above sea level. The data presented in this paper will be from the mid-mountain site (Raven's Nest) measurement site with the exception of the Lidar data obtained from the base site.

A high resolution Aerosol Mass Spectrometer (HR-ToFAMS, Aerodyne Research Inc.) was used to measure submicron aerosol mass and composition at Raven's Nest. Groundbased Lidar measurements were taken from the Lidar located at the Whistler Weather Station at Whistler Village. The Lidar is a dual-wavelength upward-pointing aerosol Lidar using an Nd:YAG pulsed 10-Hz Laser that is emitted at both the $1064 \mathrm{~nm}$ and $532 \mathrm{~nm}$ wavelengths. Details on the complete set of measurements can be found in Pierce et al. (2012) and Macdonald et al. (2012).

\subsection{GEOS-Chem model}

Predictions of SOA in this paper are from the chemical transport model, GEOS-Chem (version 9.1.1 with GEOS-5 meteorology) (http://www.geos-chem.org). The model was configured for 47 vertical layers and run globally for horizontal grid resolutions of $4^{\circ} \times 5^{\circ}$ and $2^{\circ} \times 2.5^{\circ}$ as well as regionally over North America at a horizontal resolution of $0.5^{\circ} \times 0.667^{\circ}$. Chemical boundary conditions for the $0.5^{\circ} \times 0.667^{\circ}$ simulation are taken from the $2^{\circ} \times 2.5^{\circ}$ simulation. Figure 1 shows the spatial resolution of the grid box that contains Whistler, $\mathrm{BC}$ at each of the three resolutions on a map of North America.
Incorporated within GEOS-Chem is the Model of Emissions of Gases and Aerosols from Nature (MEGAN) v2.1 (Guenther et al., 2006; Barkley et al., 2011). MEGAN is a computational VOC scheme, assimilated from many different field and laboratory studies that measured the properties and emissions of biogenic VOCs. The emissions fluxes (EM) in MEGAN are calculated in $\mu \mathrm{g} \mathrm{m}^{-2} \mathrm{~h}^{-1}$ and are given by Eq. (1):

$\mathrm{EM}=\varepsilon \cdot \gamma_{\mathrm{CE}} \cdot \gamma_{\mathrm{AGE}} \cdot \gamma_{\mathrm{SM}} \cdot \rho \gamma_{\mathrm{CE}}=\gamma_{\mathrm{LAI}} \cdot \gamma_{\mathrm{P}} \cdot \gamma_{\mathrm{T}}$

where $\varepsilon$ is the emission factor in $\mu \mathrm{g} \mathrm{m}^{-2} \mathrm{~h}^{-1}, \rho$ is the loss and production within plant canopy, $\gamma_{\mathrm{CE}}$ is the canopy factor, $\gamma_{\mathrm{AGE}}$ is the leaf age factor, $\gamma_{\mathrm{SM}}$ is the soil moisture factor, $\gamma_{\mathrm{LAI}}$, is the leaf area index factor, $\gamma_{\mathrm{P}}$ is the PPFD (Photosynthetic Photon Flux Density) emission activity factor (light dependence) and $\gamma_{\mathrm{T}}$ is the temperature response factor. The leaf area index (LAI) factors used for these simulations were derived from MODIS. Further details on specifics of each factor and other details regarding MEGAN in GEOS-Chem can be found in Barkley et al. (2011).

The SOA scheme in GEOS-Chem 9.1.1 is a two-product semi-volatile organic partitioning scheme (Odum et al., 1997). This simulation calculates the equilibrium partitioning of organics between the gas and aerosol phases based on Pankow (1994). The simulated parent hydrocarbons are alpha and beta pinene, sabinene, carene, terpenoid ketones, limonene, terpinene, terpinolene and isoprene for naturally emitted hydrocarbons and benzene, toluene and xylene for the anthropogenics. These hydrocarbons react only in the gas phase via $\mathrm{OH}, \mathrm{O}_{3}$ and $\mathrm{NO}_{3}$. The reaction yields and partitioning coefficients for these species are given by Chung and Seinfeld (2002), Henze et al. (2006, 2008) and Shilling et al. (2008). Our SOA simulations do not include (1) multi-generational secondary-organic chemistry that may increase/decrease SOA due to changes in the organic volatility distribution (e.g. Robinson et al., 2007), (2) aqueousphase SOA formation (e.g. Ervens et al., 2008), (3) very-low volatility SOA (Cappa et al., 2010 and Pierce et al., 2011), (4) mass-transfer limitations due to highly viscous aerosols (e.g. Shiraiwa et al., 2012; Vaden et al., 2010) or (5) SOA interaction with inorganic aerosols (e.g. Jang et al., 2002). Thus, the results given in this paper regarding the effect of grid resolution on SOA predictions are for traditional SOA schemes and the effect of grid resolution may differ when these recent advancements are included.

In addition to SOA, the other aerosols simulated in the model are sulfate, nitrate, ammonium, hydrophilic and hydrophobic primary organic carbon, black carbon, sea salt and dust. Details on the emissions of primary aerosols as well as the processes controlling any secondary processes can be found in van Donkelaar et al. (2008).

Simulations were performed for the month of July 2010 (with 1 month of spin-up through June 2010), as well as for the month of January 2010 (again with 1 month of spin-up through December 2009) at all 3 aforementioned horizontal 


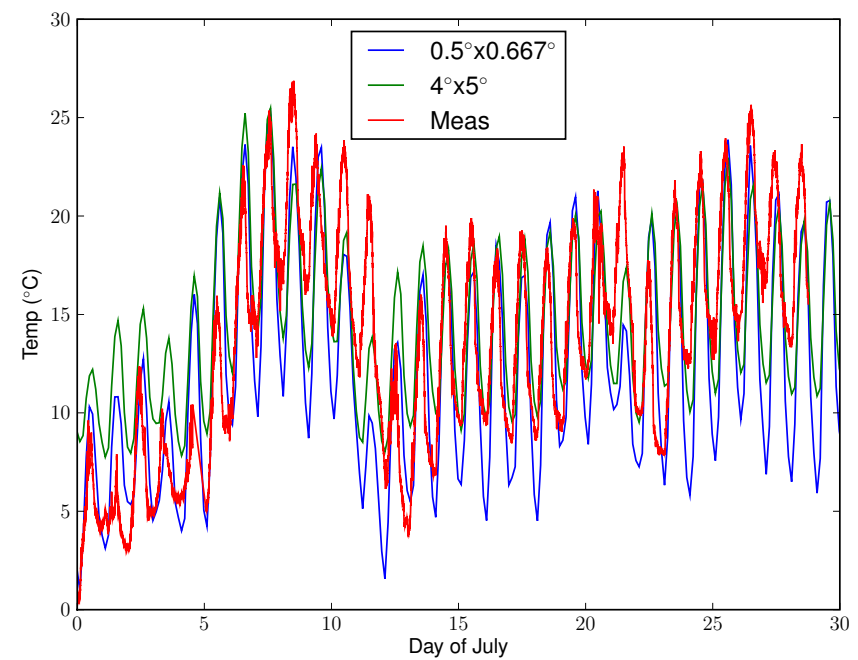

Fig. 2. Temperature at Raven's Nest for the month of July for measured and simulated data. The time is UTC.

resolutions. It should be noted that initial concentrations in the model prior to the one month spin up are from a one year spin up of the $4 \times 5$ model. For comparison with WACS 2010, model output was taken from the vertical layer in the model corresponding to the height closest to that of Raven's Nest $(\sim 1300$ ma.s.l.). The nocturnal mixed layer height in the GEOS5 meteorology is often significantly lower than in GEOS4 and GEOS3, and this led to an over prediction of nighttime concentrations in the model (http://wiki. seas.harvard.edu/geos-chem/index.php/GEOS-5 issues). To reduce the severity of this issue, we specified a minimum boundary layer height of $375 \mathrm{~m}$ above the model surface, corresponding to the top of the 3 rd vertical layer of the model.

\section{Results}

\subsection{Comparison to WACS 2010 campaign}

Figure 2 shows the measured temperature at Raven's Nest compared with the temperatures from the $4^{\circ} \times 5^{\circ}$ and $0.5^{\circ} \times 0.667^{\circ}$ resolutions for the July simulations. Temperature is an important variable contributing to changes in SOA concentrations (Leaitch et al., 2010). As can be seen, the simulations capture both the diurnal and synoptic changes in temperature. The high-resolution simulations generally predict colder temperatures at night than the measurements. However, these results show that the model temperatures at Whistler should not greatly limit the ability for either model resolution to capture SOA variability.
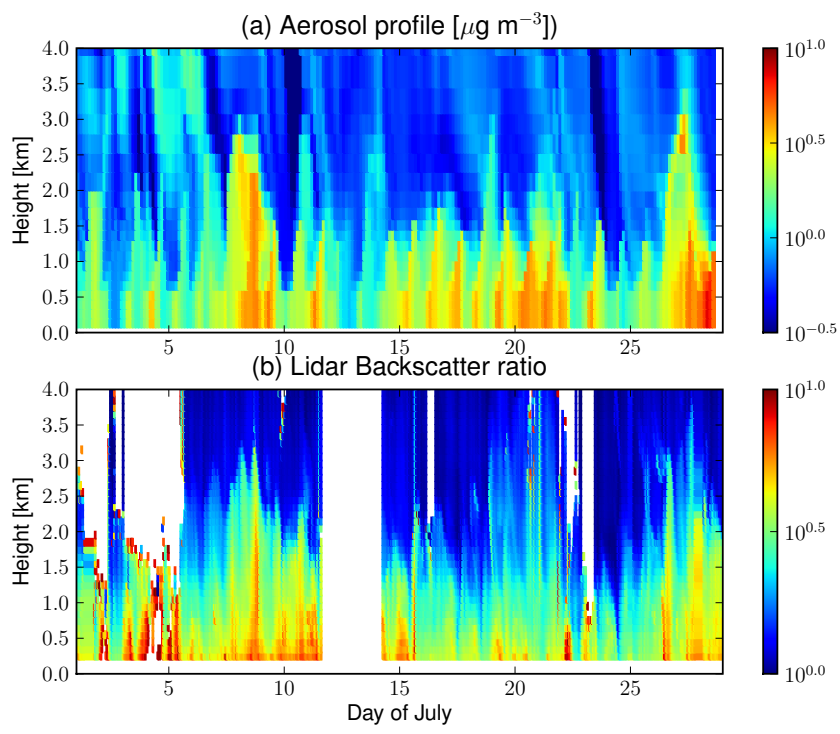

Fig. 3. (a) The simulated aerosol vertical profile (sulfates+organics) for the $0.5^{\circ} \times 0.667^{\circ}$ resolution, and (b) the measured LIDAR backscatter ratio at Whistler. The time is UTC. White spaces in the Lidar data are the result of clouds, which are masked as they result in a backscatter ratio much greater than that of aerosols. Between approximately the 12 and 14 July, the Lidar was not functioning (also white).

Figure $3 \mathrm{a}$ shows the $0.5^{\circ} \times 0.667^{\circ}$-resolution simulated aerosol vertical concentration profile for the event period (sulfate and organic aerosol only, which dominated accumulation-mode aerosol concentrations during this time period), while Fig. 3b shows the measured Lidar backscatter ratio for the same time period. Though backscatter ratio and aerosol mass are not exactly linearly proportional (backscatter ratio is also dependent on aerosol size and composition) the comparison of the two profiles can be used as a method to evaluate mixing height in the model. Overall the simulation predicts a boundary layer height similar to the measured data. The model predicts a typical mixing height of $\sim 1.5 \mathrm{~km}$, while the observations show a relatively constant mixing height between 1 and $2 \mathrm{~km}$. This comparison gives us some confidence in the ability of the model to handle vertical mixing of aerosols in the region even though upslope and downslope flows along the mountain may be difficult for the model to capture. As a result we do not expect significant errors or biases in SOA at the surface driven by errors or biases in mixing height.

Figure 4 shows the measured and modeled organic aerosol concentrations at Whistler throughout July for the three grid resolutions- (a) represents the $4^{\circ} \times 5^{\circ}$, (b) the $2^{\circ} \times 2.5^{\circ}$ and (c) the $0.5^{\circ} \times 0.667^{\circ}$ simulations. The dominance of the total organic aerosol (OA) by SOA at all model resolutions is consistent with the analyses of the measured data from the WACS 2010 campaign which suggested that most of the measured organic mass was biogenic SOA (Macdonald et al., 

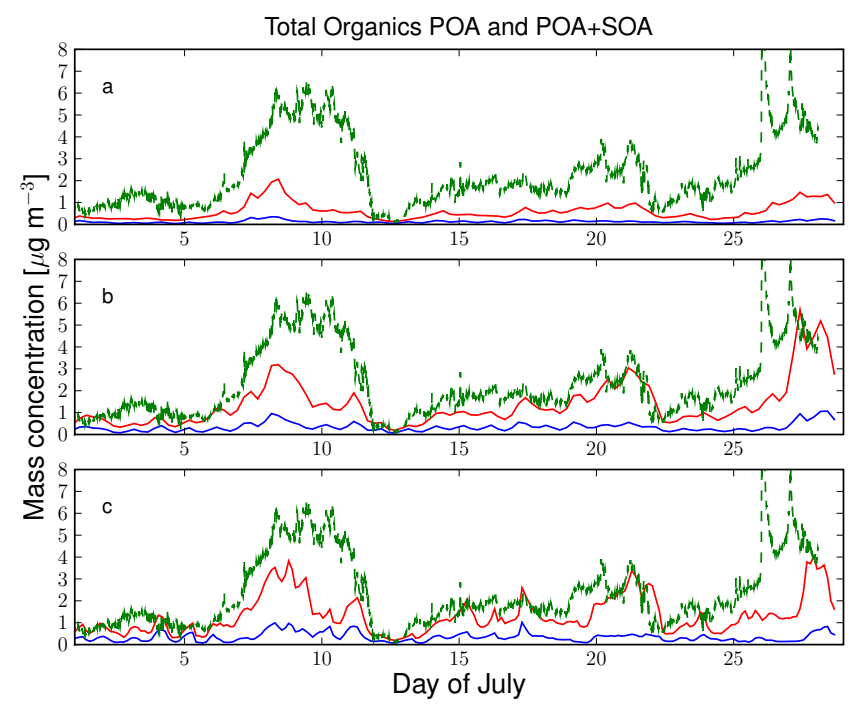

Fig. 4. Time series of organic aerosol concentrations for each simulated resolution and measurements. Simulated POA is shown in blue, while the combination of SOA and POA (total OA) is shown in red. The measured organic concentrations are green. Panel (a) is $4^{\circ} \times 5^{\circ}$, (b) $2^{\circ} \times 2.5^{\circ}$ and (c) $0.5^{\circ} \times 0.667^{\circ}$. The time is UTC.

2012). A significant feature of Fig. 4 is that the $2^{\circ} \times 2.5^{\circ}$ and $0.5^{\circ} \times 0.667^{\circ}$ simulations each contain a large contribution from SOA to total organic mass for the entire month. The predicted SOA at Whistler compares better for horizontal model resolutions of $\sim 200 \mathrm{~km}$ or less. The $4^{\circ} \times 5^{\circ}$ grid box includes a large portion of the Pacific Ocean (Fig. 1), which is an area with little to no organic aerosol emissions or SOA formation. This ocean grid-box fraction is likely a large contributing factor to the low predictions by the model at the $4^{\circ} \times 5^{\circ}$ resolution.

The correlation coefficients for the three simulations with the measured organic aerosol concentrations were $0.52,0.48$ and 0.32 for $0.5^{\circ} \times 0.667^{\circ}, 2^{\circ} \times 2.5^{\circ}$ and $4^{\circ} \times 5^{\circ}$ respectively. The calculated mean biases for each simulation (in the same order) were $-0.92,-0.84$ and $-1.6 \mu \mathrm{g} \mathrm{m}^{-3}$. The calculated normalized mean biases (again in the same order) were $-0.41,-0.38$ and -0.73 . The correlations and biases favor the higher resolution simulations (for $0.5^{\circ} \times 0.667^{\circ}$ and $2^{\circ} \times 2.5^{\circ}$ ); although the differences between the two higher resolution simulations are not significant. While the model is biased low by $\sim 40 \%$ even at the highest resolution, this comparison suggests that model resolution may be one potential reason for the common low bias of organic aerosol concentrations in models (e.g. Heald et al., 2005; Volkamer et al., 2006).

\subsection{Comparisons between resolutions across North America}

In the previous section, we showed that coarsest spatial resolution (e.g. $4^{\circ} \times 5^{\circ}$ ) does not capture the SOA concentrations and variability at Whistler. This is due in part to the model grid box extending over the Pacific Ocean. In addition, the topography surrounding the Whistler mountain valley makes it extremely difficult for any low-resolution model to resolve properly. Upslope/downslope mountain winds cannot be resolved properly even by our highest resolution simulations $\left(0.5^{\circ} \times 0.667^{\circ}\right)$. However, it is unclear how SOA concentrations depend on the grid resolution in other locations. In this section, we determine what locations in North America are susceptible to changes in SOA concentrations with changing model resolutions. We also investigate the sources of the SOA changes (e.g. emissions, partitioning and lifetime).

In order to determine how SOA predictions depend on grid resolution throughout North America, we compare results of the $0.5^{\circ} \times 0.667^{\circ}$ and $4^{\circ} \times 5^{\circ}$ simulations. To do this, we calculate the mean SOA concentration of the $0.5^{\circ} \times 0.667^{\circ}$ grid boxes within each $4^{\circ} \times 5^{\circ}$ grid box for each model output time (every $6 \mathrm{~h}$ ). For each $4^{\circ} \times 5^{\circ}$ grid box there were $8 \times 0.5^{\circ} \times 0.667^{\circ}$ grid boxes latitudinally and 7.5 longitudinally. We refer to these new $4^{\circ} \times 5^{\circ}$ values calculated as the average of the $0.5^{\circ} \times 0.667^{\circ}$ values as the scaled-up (SU) values. The same comparison was done with $0.5^{\circ} \times 0.667^{\circ}$ and $2^{\circ} \times 2.5^{\circ}$ and the results from that analysis will also be presented in this section. As mentioned previously, both a summer (July) and winter (January) case were simulated and the plots shown represent the results from the July simulations.

Figure 5a shows the time-averaged SOA concentrations for the month of July, 2010 for $4^{\circ} \times 5^{\circ}$ over most of North America, while Fig. 5b shows the time-averaged SOA for the $0.5^{\circ} \times 0.667^{\circ}$ simulation during the same time period. Figure 5c shows the average SU values for SOA. Accordingly, the SU patterns match closely with the $0.5^{\circ} \times 0.667^{\circ}$ simulations. In the absence of (1) changes in the partitioning of secondary organic matter (SOM, which is the sum of secondary organic products in both the aerosol and gas phases) between the gas-phase and aerosol phase, (2) changes in SOA precursor emissions from MEGAN (which are non-linearly dependent on temperature and leaf area index) or (3) changes in aerosol lifetime between the $0.5^{\circ} \times 0.667^{\circ}$ and $4^{\circ} \times 5^{\circ}$ simulations, the SOA mass concentrations in Fig. 5a and c should be the same. The average of $0.5^{\circ} \times 0.667^{\circ}$ and SU concentrations, however, are significantly higher $\left(\sim 2 \mu \mathrm{g} \mathrm{m}^{-3}\right)$ in some places than those of the $4^{\circ} \times 5^{\circ}$. This means that variability in parameters with spatial scales smaller than $4^{\circ} \times 5^{\circ}$ resolution cause changes in emissions, lifetime and/or SOM partitioning such that the $4^{\circ} \times 5^{\circ}$ simulations predict lower SOA concentrations (on average) relative to higher resolution simulations. 

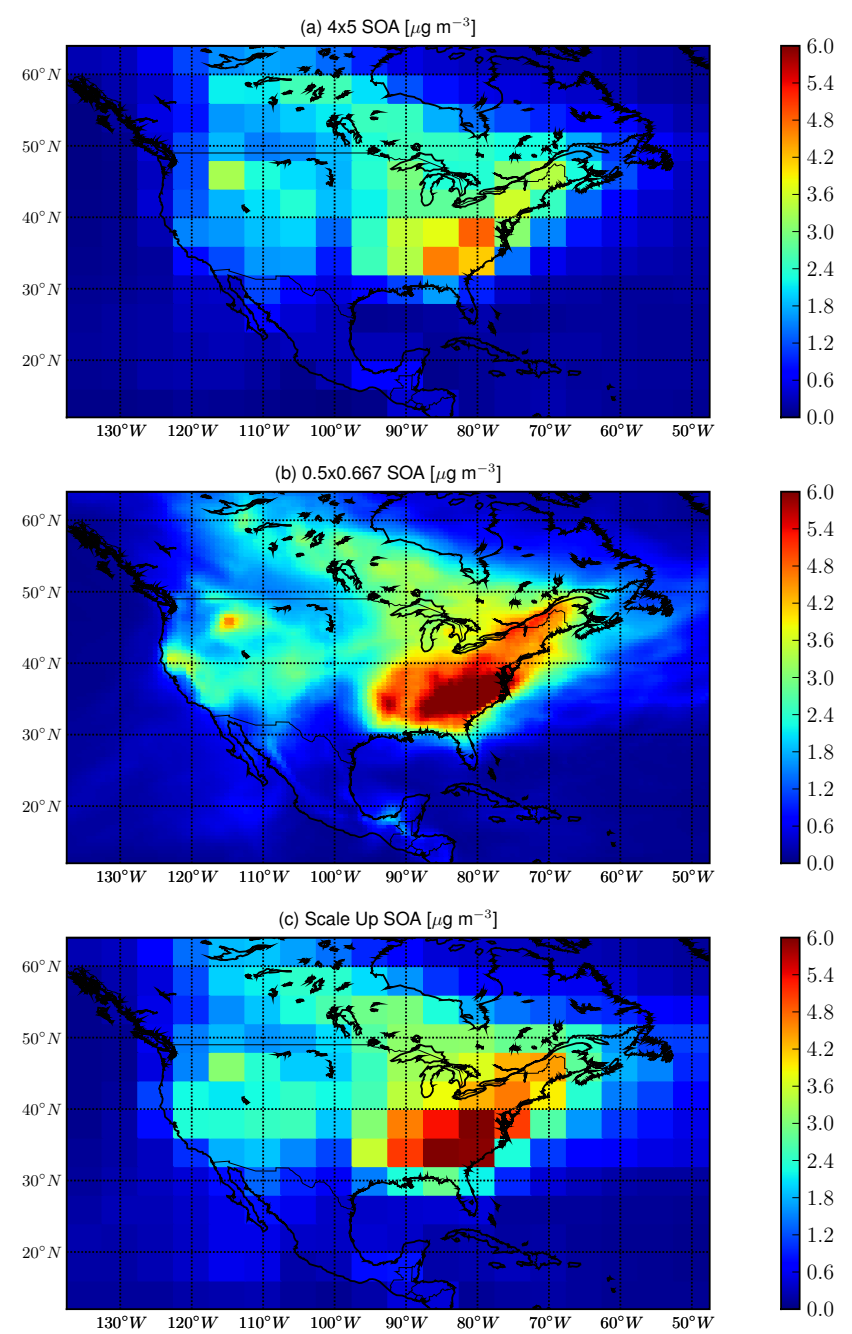

Fig. 5. Averaged SOA concentrations for the month of July over of North America. Panel (a) represents the $4^{\circ} \times 5^{\circ}$ simulation, (b) the $0.5^{\circ} \times 0.667^{\circ}$ simulation and (c) the scaled up (SU) average of the $0.5^{\circ} \times 0.667^{\circ}$ boxes in each $4^{\circ} \times 5^{\circ}$ box.

Figure 6a shows the percent difference between the SU and $4^{\circ} \times 5^{\circ}$ values for July-averaged SOA concentrations, while Fig. 6b shows the absolute difference between the two. The SOA in the SU simulation is higher than the SOA in the $4^{\circ} \times 5^{\circ}$ simulation across almost the entire spatial domain, with increases extending above $100 \%$ in near-coastal oceanic regions (or regions with very low SOA levels). Table 1 shows the total-domain-sum ratios of the $0.5^{\circ} \times 0.667^{\circ}$ simulation to the two coarser simulations for various model factors including the SOA concentrations for both the summer and winter case. In these ratios, the SOA mass is summed across the North American spatial domain before the ratio is taken, so regions with low SOA concentrations do not greatly influence the domain-wide ratios. For the July simulations, the average increase between the $4^{\circ} \times 5^{\circ}$ and the $0.5^{\circ} \times 0.667^{\circ}$ (averaged over the $4^{\circ} \times 5^{\circ}$ grid) SOA con-
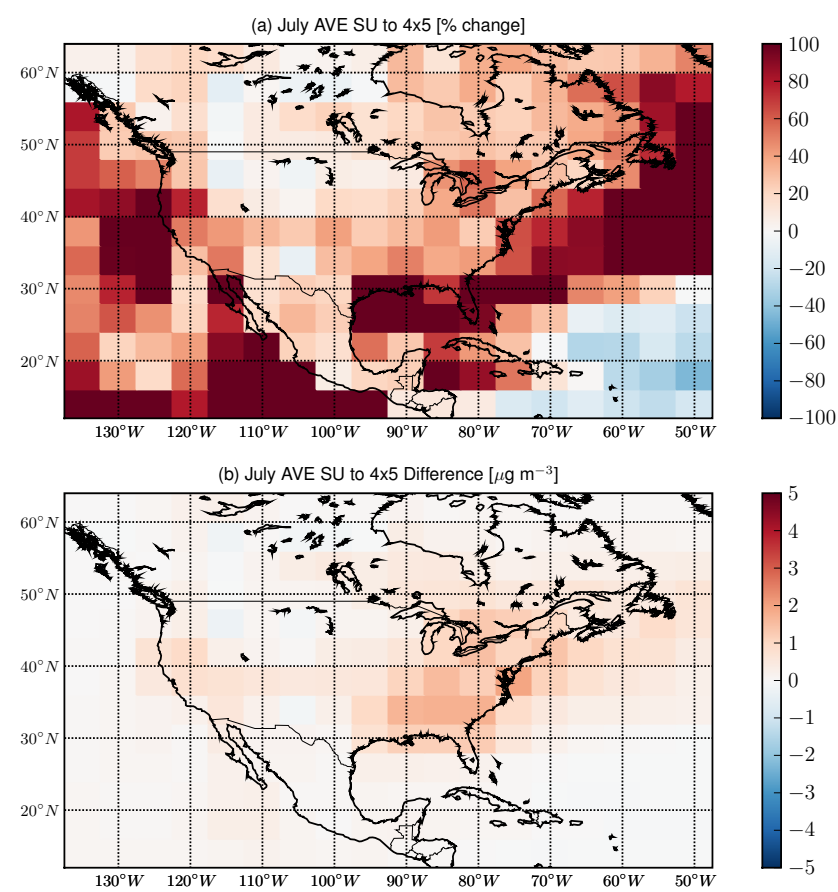

Fig. 6. SOA comparisons between the scaled up $0.5^{\circ} \times 0.667^{\circ} \mathrm{sim}-$ ulations (SU) and the $4^{\circ} \times 5^{\circ}$ simulations averaged over July. Panel (a) is the $\%$ difference between the SU and $4^{\circ} \times 5^{\circ}$ SOA and (b) is the absolute difference $\left(\mu \mathrm{g} \mathrm{m}^{-3}\right)$.

centrations was $32 \%$. The SOA in the $2^{\circ} \times 2.5^{\circ}$ simulations is in between the two other resolutions with the ratio of the SOA from $0.5^{\circ} \times 0.667^{\circ}$ (averaged over the $2^{\circ} \times 2.5^{\circ}$ grid) being $19 \%$ higher than the SOA from the $2^{\circ} \times 2.5^{\circ}$ simulation. The winter simulation yielded similar but smaller overall increases with an average increase of $23 \%$ between the $4^{\circ} \times 5^{\circ}$ and $0.5^{\circ} \times 0.667^{\circ}$ simulations and $8 \%$ between the $2^{\circ} \times 2.5^{\circ}$ and the $0.5^{\circ} \times 0.667^{\circ}$ simulations.

The percent difference plot (Fig. 6a) shows large differences between resolutions along the ocean-continent boundaries, where the mixing of marine and continental air in these grid boxes may affect the partitioning of SOM between the gas and aerosol phases. Thus, it is likely that the poor performance of the $4^{\circ} \times 5^{\circ}$ simulations at Whistler were partially explained by this effect. For reference, the monthly mean OA concentrations at Whistler were $1.96 \mu \mathrm{g} \mathrm{m}^{-3}$ for the measurements, $1.55 \mu \mathrm{g} \mathrm{m}^{-3}$ in the $0.5^{\circ} \times 0.667^{\circ}$ simulation, $1.41 \mu \mathrm{g} \mathrm{m}^{-3}$ in the SU simulation and $1.13 \mu \mathrm{g} \mathrm{m}^{-3}$ in the $4^{\circ} \times 5^{\circ}$ simulation. The difference between the SU case and the $0.5^{\circ} \times 0.667^{\circ}$ simulation shows this ocean-boundary effect.

In order to investigate the reasons for the increase in SOA with increased grid resolution, we also looked at changes in the total amount of SOM. Figure 7a shows the percent difference of SU SOM to $4^{\circ} \times 5^{\circ} \mathrm{SOM}$, while Fig. $7 \mathrm{~b}$ shows the absolute difference between the two. The relative and absolute amounts of SOM increase with resolution similarly to 
Table 1. The ratios of SOA and SOM properties between the $0.5^{\circ} \times 0.667^{\circ}$ and $4^{\circ} \times 5^{\circ}$ simulations over North America.

\begin{tabular}{lcccc}
\hline Model Variable & $\begin{array}{c}0.5^{\circ} \times 0.667^{\circ} \text { to } \\
4^{\circ} \times 5^{\circ} \text { ratio } \\
(\mathrm{July})\end{array}$ & $\begin{array}{c}0.5^{\circ} \times 0.667^{\circ} \text { to } \\
2^{\circ} \times 2.5^{\circ} \text { ratio } \\
(\mathrm{July})\end{array}$ & $\begin{array}{c}0.5^{\circ} \times 0.667^{\circ} \text { to } \\
4^{\circ} \times 5^{\circ} \text { ratio } \\
(\text { January })\end{array}$ & $\begin{array}{c}0.5^{\circ} \times 0.667^{\circ} \text { to } \\
2^{\circ} \times 2.5^{\circ} \text { ratio } \\
(\text { January })\end{array}$ \\
\hline Emissions (Isoprene and Monoterpenes) & 0.99 & 0.97 & 1.07 & 1.03 \\
SOM lifetime & 1.12 & 1.13 & 1.02 & 1.04 \\
Partitioning ratio (PR, SOA/SOM) & 1.19 & 1.09 & 1.10 & 1.02 \\
Emissions*Lifetime*PR & 1.32 & 1.19 & 1.20 & 1.09 \\
SOA & 1.32 & 1.19 & 1.23 & 1.08
\end{tabular}
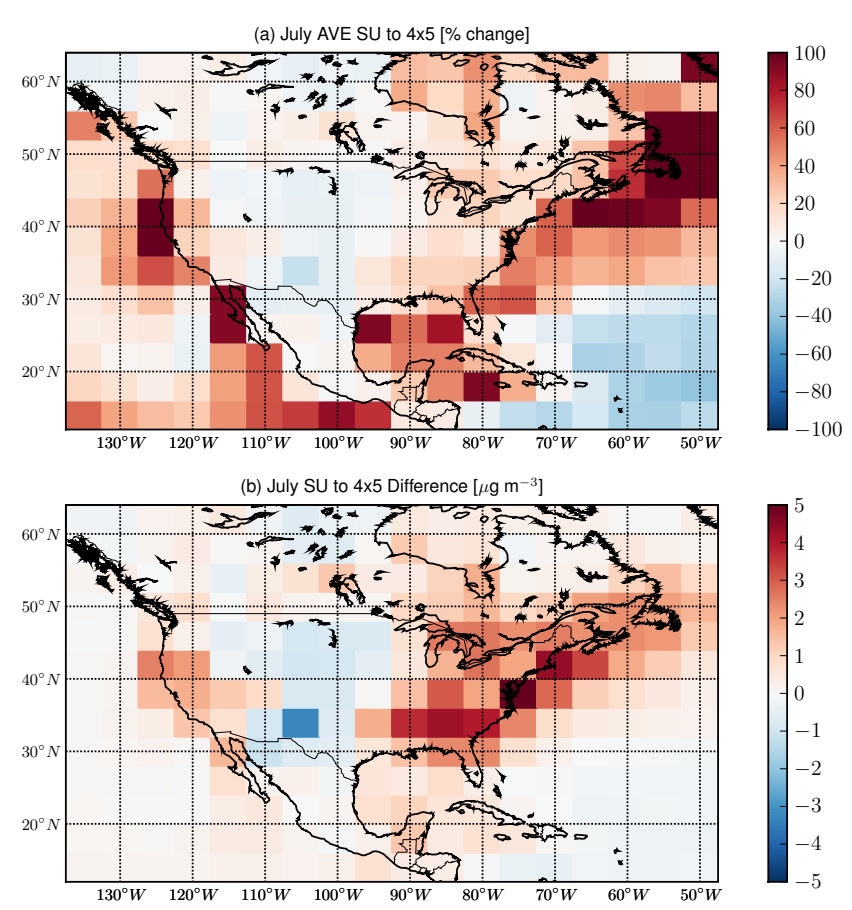

Fig. 7. SOM comparisons between the scaled up $0.5^{\circ} \times 0.667^{\circ}$ simulations (SU) and the $4^{\circ} \times 5^{\circ}$ simulations averaged over July. Panel (a) is the \% difference between the SU and $4^{\circ} \times 5^{\circ} \mathrm{SOM}$ and (b) is the absolute difference $\left(\mu \mathrm{g} \mathrm{m}^{-3}\right)$.

the SOA in Fig. 6. The relative change in SOM (Fig. 7a) is not as large as the change in SOA (Fig. 6a). Thus, there is a smaller fractional increase in the secondary organic gases than the SOA (or perhaps a slight decrease in secondary organic gases) between the $4^{\circ} \times 5^{\circ}$ and $0.5^{\circ} \times 0.667^{\circ}$ simulations. However, the absolute changes in the SOM (Fig. 7b) are generally larger than the changes in SOA between the two resolutions (Fig. 6b). In order for SOM to increase in the model, either the emissions of SOA precursors is greater at higher resolution, or the lifetime of the resultant secondary organic matter is longer at higher resolution.

Isoprene and monoterpenes represent the largest contributors to SOA in GEOS-Chem 9.1.1, and we use these two species to investigate the changes in the emissions of SOA precursor gases with emissions. Figure $8 \mathrm{a}$ and $\mathrm{b}$ show us the relative and absolute difference between the $\mathrm{SU}$ and $4^{\circ} \times 5^{\circ}$ July averaged isoprene emissions. Figure $9 \mathrm{a}$ and $\mathrm{b}$ give the same plots but for monoterpene emissions. As can be seen in both the isoprene and monoterpene figures, there is very little relative change between the $4^{\circ} \times 5^{\circ}$ and SU simulations for either, except for along the coastlines (Figs. 8a and 9a) where the $4^{\circ} \times 5^{\circ}$ grid boxes contain both ocean and land portions. The coasts affect the total isoprene and monoterpene emissions from the MEGAN inventory because the emissions depend non-linearly with leaf-area index (which is non-zero over land and zero over oceans). The absolute differences (Figs. 8b and 9b) show areas of decreases over the continents; however, these represent very small relative changes in emissions (Figs. 8a and 9a). For the summer case, the domain average change in emissions (combined isoprene and monoterpenes) between the simulations was a $-1 \%$ change between $4^{\circ} \times 5^{\circ}$ and $0.5^{\circ} \times 0.667^{\circ}$ and $\mathrm{a}-3 \%$ change between $2^{\circ} \times 2.5^{\circ}$ and $0.5^{\circ} \times 0.667^{\circ}$, while the winter case showed an average change of $7 \%$ between $4^{\circ} \times 5^{\circ}$ and $0.5^{\circ} \times 0.667^{\circ}$ and a $3 \%$ change between $2^{\circ} \times 2.5^{\circ}$ and $0.5^{\circ} \times 0.667^{\circ}$ as shown in Table 1 . The variation between the summer and winter emissions ratios is likely due to the effects of several non-linear emission activity factors in MEGAN used in predicting emissions (e.g. leaf-area index, temperature, sunlight). Most significantly, within the model parameters, as variability in Leaf Area Index (LAI) increases, emissions decrease. Thus, as we get larger variability with increasing resolution, we see a drop in emissions across NA. Overall, the $\%$ change in emissions is a generally a small to moderate effect and cannot explain most of the SOA changes. The increase in SOA and SOM with increasing resolution must therefore be affected by other factors such as SOM lifetime and partitioning ratio.

Table 1 shows the results of the domain-average differences in SOM lifetime (calculated using the SOM burden divided by the SOM formation rates within the North American domain; the SOM formation rates are essentially proportional to the emissions rates showing that changes in chemistry with resolution is negligible overall) between resolutions, with a domain average increase of $12 \%$ between the $0.5^{\circ} \times 0.667^{\circ}$ simulation and the $4^{\circ} \times 5^{\circ}$ simulation, $13 \%$ 

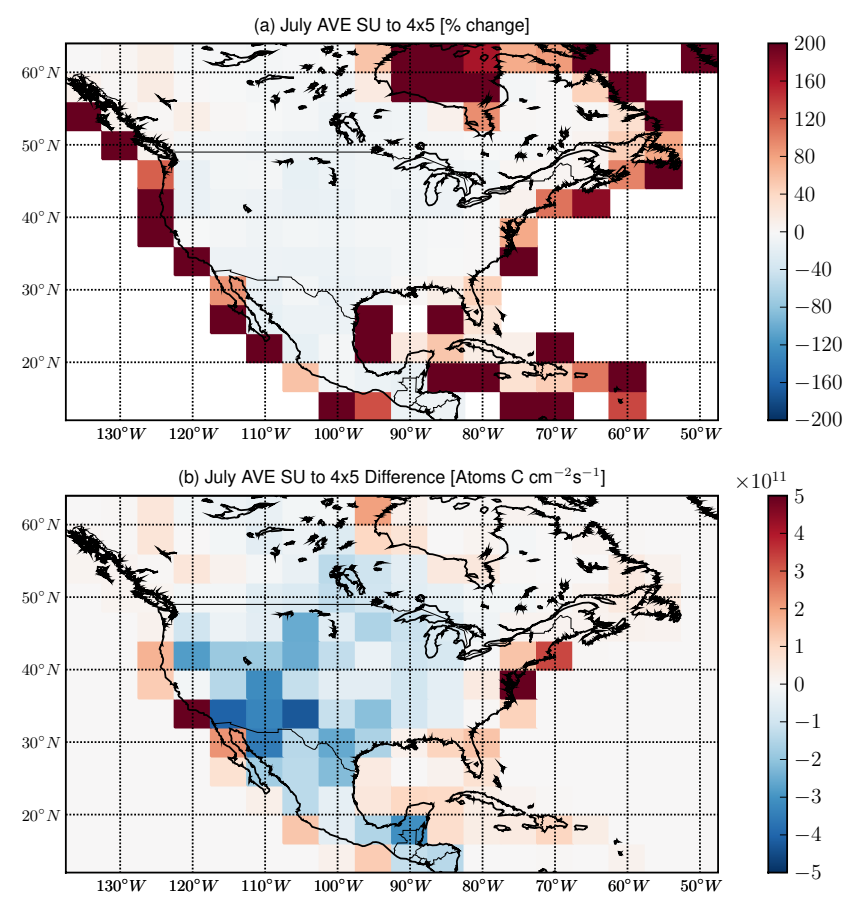

Fig. 8. Isoprene emission comparisons between the scaled up $0.5^{\circ}$ $\times 0.667^{\circ}$ simulations (SU) and the $4^{\circ} \times 5^{\circ}$ simulations averaged over July. Panel (a) is the \% difference between the SU and $4^{\circ} \times 5^{\circ}$ isoprene emissions and (b) is the absolute difference (atoms $\mathrm{C}$ $\left.\mathrm{cm}^{-2} \mathrm{~s}^{-1}\right)$.

between the $0.5^{\circ} \times 0.667^{\circ}$ simulation and the $2^{\circ} \times 2.5^{\circ}$ simulation for the summer case and $2 \%$ and $4 \%$ respectively for the winter case. These lifetime differences could be due to differences in meteorology (e.g. rain rates that would affect wet deposition rates) between model resolutions; however, the lifetimes of other species, such as primary organic aerosol (POA) and sulfate show much smaller lifetime changes $(\sim 1-$ $2 \%$ ) between resolutions. In order to understand the reason for the predicted change in lifetime (as well as other reasons for the increase in SOA) we investigate the SOM partitioning between the gas and aerosol phases.

Figure 10a shows the relative percent change in partitioning of SOM to the aerosol phase (SOA/SOM, given as the percent of SOM in the aerosol phase) between SU and $4^{\circ} \times 5^{\circ}$, while Fig. $10 \mathrm{~b}$ shows the absolute difference in partitioning between the two resolutions. As can be seen, there is a positive change in the partitioning between the $0.5^{\circ} \times 0.667^{\circ}$ and $4^{\circ} \times 5^{\circ}$ simulations. As shown in Table 1 , the domain average increase in partitioning of SOM to the aerosol phase was $19 \%$ between $0.5^{\circ} \times 0.667^{\circ}$ simulation and $4^{\circ} \times 5^{\circ}$ simulation, and $9 \%$ between the $0.5^{\circ} \times 0.667^{\circ}$ simulation and the $2^{\circ} \times 2.5^{\circ}$ simulation for the summer case and a $10 \%$ and $2 \%$ increase for the same comparisons for the winter case.

The reason for the increase in the partitioning of SOM to SOA is as follows. The higher resolution simulations will re-
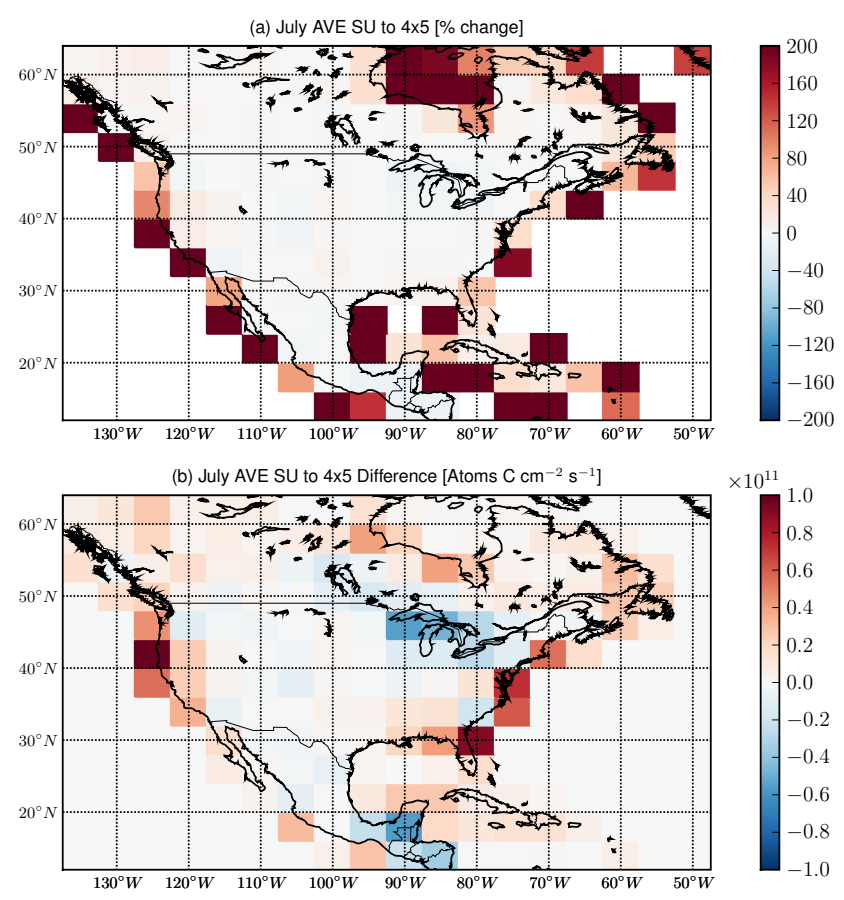

Fig. 9. Monoterpene emissions comparisons between the scaled up $0.5^{\circ} \times 0.667^{\circ}$ simulations (SU) and the $4^{\circ} \times 5^{\circ}$ simulations averaged over July. Panel (a) is the \% difference between the SU and $4^{\circ} \times 5^{\circ}$ monoterpene emissions and (b) is the absolute difference (atoms $\mathrm{C} \mathrm{cm}^{-2} \mathrm{~s}^{-1}$ ).

solve emission hotspots of organic matter that include both POA and SOM (Fig. 11). The presence of POA increases the partitioning of SOM to SOA as a result of the model allowing SOA mass to partition into the total organic aerosol mass. These hotspots include cities or forests with large emissions of SOA precursors and POA. The coarser resolution simulations will blend these hotspots with regions of lower amounts of organic matter. While higher resolution simulations also resolve regions of low organic matter concentrations yielding lower partitioning ratios in these regions, most of the SOM mass is contained in hotspot regions (or regions with SOM values higher than the mean). Thus, the increase in resolution leads to an overall increase in partitioning of SOM to SOA relative to coarse resolution simulations. Figure 12 shows offline calculations of the enhancement of SOA concentrations in a fine grid model relative to a coarse grid model using the monoterpene-SOA partitioning parameters from GEOSChem. These calculations are independent of the resolution of the fine and coarse grids, and they only depend on the mean SOM concentration in the coarse grid box and the standard deviation of the SOM within the coarse grid box. The average increase in SOA in the fine grid above the coarse grid is in the range of $5-30 \%$ for the typical SOM concentrations over the continent predicted by GEOS-Chem (5$20 \mathrm{\mu g} \mathrm{m}^{-3}$ ) and the typical normalized standard deviations of SOM within the coarse grid box over the continent predicted 

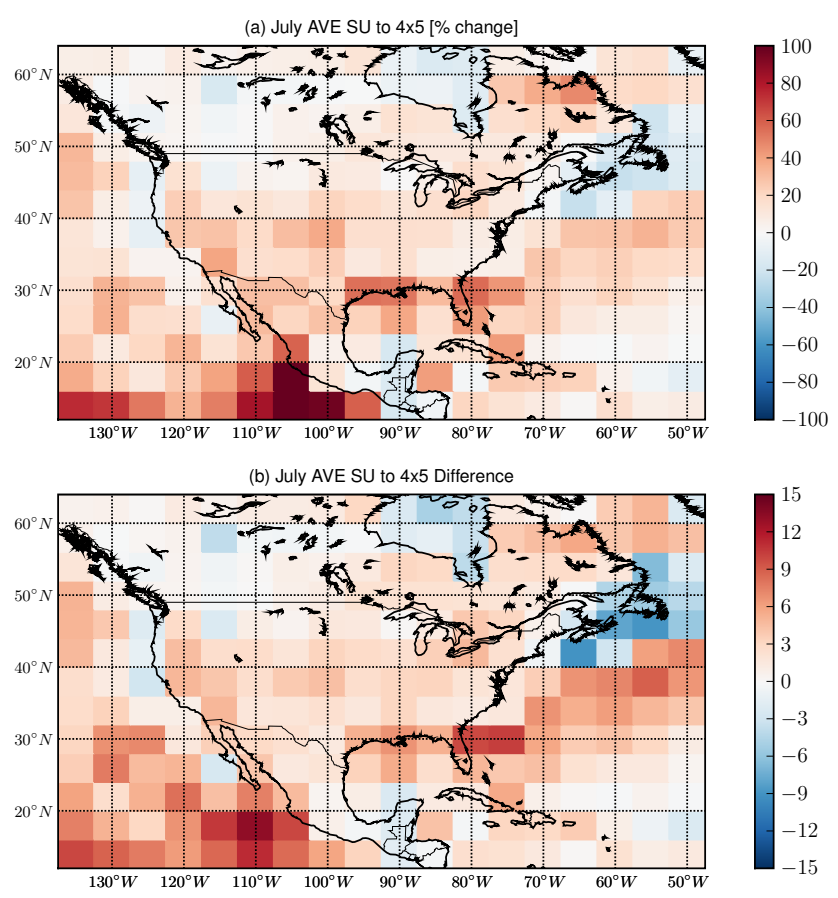

Fig. 10. SOM partitioning ratio (SOA/SOM) comparisons between the scaled up $0.5^{\circ} \times 0.667^{\circ}$ simulations (SU) and the $4^{\circ} \times 5^{\circ}$ simulations averaged over July. Panel (a) is the \% difference between the $\mathrm{SU}$ and $4^{\circ} \times 5^{\circ}$ partitioning ratios and (b) is the absolute difference (also units of percent since the partitioning ratio is also calculated as a percent).

by GEOS-Chem (0.5-0.8). This exercise shows that the partitioning of SOM to the aerosol phase in GEOS-Chem increases with increasing model resolution due to variability in SOM and POA concentrations on grid scales smaller than the coarse grid resolutions. These results were also seen in Stroud et al. (2011) for even smaller resolutions (between $2.5 \mathrm{~km}$ and $42 \mathrm{~km}$ ) of the AURAMS model, which shows that this increased-partitioning effect due to hotspots continues as model resolutions are increased beyond the highest resolutions tested in this paper with GEOS-Chem $(\sim 50 \mathrm{~km})$. Thus, the predictions at even the highest resolution tested in this paper $\left(0.5^{\circ} \times 0.667^{\circ}\right)$ may still be biased low due to subgrid variability in SOM and POA. Additionally, Stroud et al. (2011) suggested that a portion of the changes in partitioning may also be due to non-linear changes in chemistry with changes in resolution as higher resolution simulations would better resolve high- $\mathrm{NO}_{\mathrm{x}}$ and low- $\mathrm{NO}_{\mathrm{x}}$ SOA-chemistry regimes. However, these GEOS-Chem simulations do not contain separate high- $\mathrm{NO}_{\mathrm{x}}$ and low- $\mathrm{NO}_{\mathrm{x}} \mathrm{SOA}$-yield parameters for monoterpenes and isoprene, the two most dominant contributors to SOA over North America.

The increase in partitioning to the aerosol phase with increasing resolution has two important implications for the amount of SOA: (1) the amount of SOA increases directly as the result of increased partitioning of SOM to the aerosol

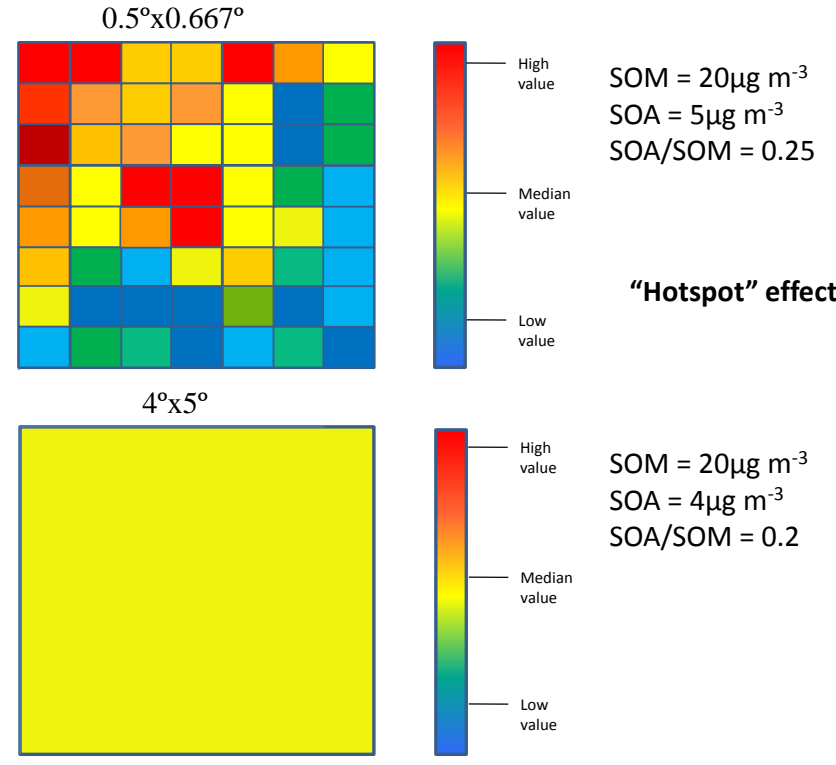

Fig. 11. A representation of the "hotspot" effect that affects the partitioning of SOM between resolutions in the model. Higherresolution simulations will resolve variability in SOM and POA (POA not shown). In GEOS-Chem, resolving this variability leads to increases in SOA partitioning in regions of high SOM (or POA), and decreases in SOA partitioning in regions of low SOM (or POA). The regions with SOA partitioning decreases do not fully compensate for the regions with increases because more SOM mass is contained in the hotspot regions.

phase and (2) the lifetime of SOM increases with increased partitioning to the aerosol phase. The SOM lifetime increases because more SOM is in the aerosol phase rather than the gas phase at high resolutions. The lifetime of secondary organic gases in the GEOS-Chem have, on average, a shorter lifetime than SOA due to significantly faster removal via dry deposition. The enhanced dry deposition of secondary organic gases is due to faster diffusion through the quasi-laminar sub layer by gases than aerosols. Thus, as more SOM partitions to the aerosol phase, the SOM lifetime increases. This explains the increases in SOM lifetime with increasing resolution as discussed earlier (Table 1). This increase in SOM concentrations through the lifetime effect further increases the partitioning ratio (SOA/SOM), albeit by a smaller amount than the "hotspot effect" discussed above. The increased yield is why the relative changes in SOA with resolution (Fig. 6a) are larger than the relative changes in SOM (Fig. 7a). Thus, this "hotspot effect" of resolving variability in SOM and POA at higher resolution leads to increased SOA concentration both due to increased yield and increased lifetime of SOM.

We calculate the product of the relative enhancements due to emissions, lifetime and yield with resolution to see if the total enhancement in SOA calculated through this method is the same as what the model predicted for the increase in SOA with resolution. Table 1 shows that for the summer 
Table 2. A comparison of the $5 \mathrm{~km}$ and surface SOA concentrations changes between different resolutions.

\begin{tabular}{lcccc}
\hline SOA change & Summer & Summer & Winter & Winter \\
\hline & $4 \times 5$ to $0.5 \times 0.667$ & $2 \times 2.5$ to $0.5 \times 0.667$ & $4 \times 5$ to $0.5 \times 0.667$ & $2 \times 2.5$ to $0.5 \times 0.667$ \\
$5 \mathrm{~km}$ & 1.51 & 1.00 & 1.19 & 1.05 \\
Surface & 1.32 & 1.19 & 1.23 & 1.08 \\
\hline
\end{tabular}

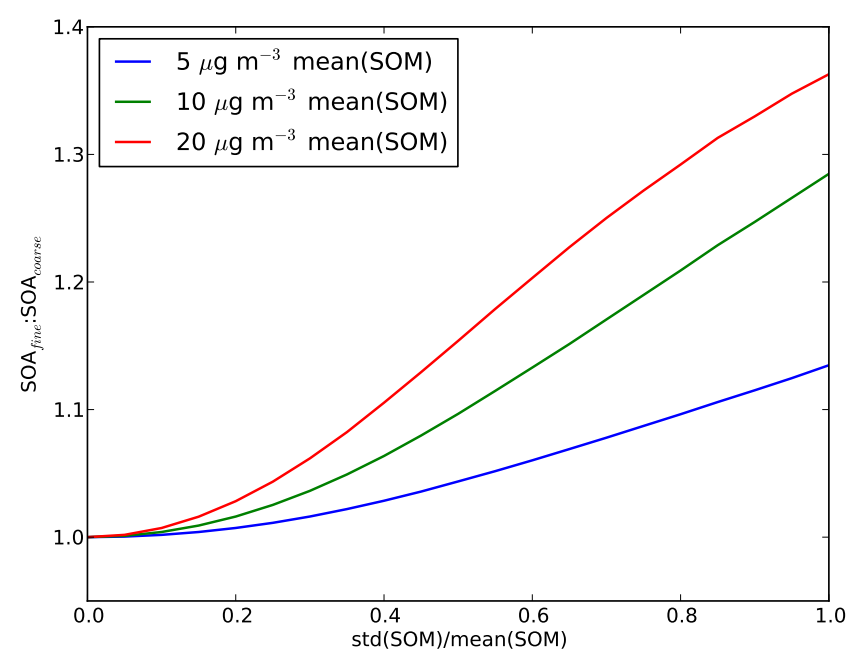

Fig. 12. The ratio of the average enhancement in monoterpene SOA for a fine resolution above a course resolution as a function of the standard deviation of SOM of the fine grid within the course grid (normalized by the mean SOM concentration).

simulations this product of the different factors matches up within two significant figures with the observed SOA increase. For the winter simulations we see similar agreement up to one significant figure. This suggests that we have identified the most significant reasons for the increase in SOA with resolution.

As previously mentioned, the same analysis was performed between the $2^{\circ} \times 2.5^{\circ}$ and $0.5^{\circ} \times 0.667^{\circ}$ simulations and is shown in Table 1. For both the summer and winter cases, the SOA increase between the resolutions is less drastic. For July, there is a $19 \%$ increase in SOA from $2^{\circ} \times 2.5^{\circ}$ to $0.5^{\circ} \times 0.667^{\circ}$ compared to a $32 \%$ increase from $4^{\circ} \times 5^{\circ}$ to $0.5^{\circ} \times 0.667^{\circ}$. For January, there is an $8 \%$ increase in SOA from $2^{\circ} \times 2.5^{\circ}$ to $0.5^{\circ} \times 0.667^{\circ}$ compared to a $23 \%$ increase from $4^{\circ} \times 5^{\circ}$ to $0.5^{\circ} \times 0.667^{\circ}$. The reason for the larger increase across resolutions in the summer compared to winter is likely related to the July case having higher concentrations of SOA. The domain average OA concentrations for the July simulation were $1.43 \mu \mathrm{g} \mathrm{m}^{-3}$, while the January simulation yielded a domain average of only $0.66 \mu \mathrm{g} \mathrm{m}^{-3}$. As the concentration is greater in the summer case, we would see a larger enhancement of SOA due to the hotspot effect (see Fig. 12).
An additional analysis was done at in the free troposphere at $5 \mathrm{~km}$ above the surface. Table 2 shows the ratio of SOA between model resolutions for the summer and winter simulations at $5 \mathrm{~km}$ compared to the surface increases. There was a $51 \%$ increase between the $4^{\circ} \times 5^{\circ}$ and $0.5^{\circ} \times 0.667^{\circ}$ for the summer at $5 \mathrm{~km}$ (compared to $32 \%$ for the surface concentrations). The $2^{\circ} \times 2.5^{\circ}$ and $0.5^{\circ} \times 0.667^{\circ}$ comparisons yielded no increase at $5 \mathrm{~km}$ (compared to $19 \%$ at the surface). The winter $5 \mathrm{~km}$ comparisons were quite similar to the surface with a $19 \%$ change between the $4^{\circ} \times 5^{\circ}$ and $0.5^{\circ} \times 0.667^{\circ}$ (compared to $23 \%$ at the surface) and a $5 \%$ change between the $2^{\circ} \times 2.5^{\circ}$ and $0.5^{\circ} \times 0.667^{\circ}$ (compared to $8 \%$ at the surface).

Most interesting in the $5 \mathrm{~km}$ comparison is that during the summer there is no fractional change in SOA between the $2^{\circ} \times 2.5^{\circ}$ and $0.5^{\circ} \times 0.667^{\circ}$, whereas there is a large change between $4^{\circ} \times 5^{\circ}$ and $0.5^{\circ} \times 0.667^{\circ}$. This may be due to horizontal concentration gradients at $5 \mathrm{~km}$ being resolved in the model at both the $2^{\circ} \times 2.5^{\circ}$ resolution $(\sim 200 \mathrm{~km}$ spatial scale), but horizontal concentration gradients require higher spatial resolutions at the surface. However, at the $4^{\circ} \times 5^{\circ}$ resolution $(\sim 400 \mathrm{~km})$ scale, these gradients may not be resolved at either altitude. This is somewhat consistent with work done in Weignum et al. (2012), which used aircraft measurements to estimate that carbonaceous aerosol plume sizes in the free troposphere had a median width of $113 \mathrm{~km}$ (with a range of $85-155 \mathrm{~km}$ ). $2^{\circ} \times 2.5^{\circ}$-resolution simulations are somewhat close to being able to resolve these plumes. However, the model is incapable however of resolving plumes of the size mentioned above at the $4^{\circ} \times 5^{\circ}$ scale due to spatial limitations.

To determine if increasing resolution and resolving the hotspot effect improves OM predictions, we compared the model results at each resolution to the IMPROVE and CSN ground networks across North America using the speciated $\mathrm{PM}_{2.5}$ data from Hand et al. (2012). Unfortunately these measurements are time averaged for 2005-2008, as the speciated time-series data for 2010 is not yet available online. We averaged the winter and summer simulations to produce a pseudo-annual mean. The correlations between model and measured values were generally weak $(r<0.4)$ with little to no change in correlations between resolutions. An analysis where the model and measurements are co-sampled can be done when the 2010 time-series data becomes available. 


\section{Conclusions}

In this paper, we investigated how the ability of the GEOSChem model (with biogenic VOC emissions from MEGAN) to reproduce biogenic SOA during the WACS 2010 campaign in Whistler, BC Canada during the summer of 2010 depends on the resolution of the model. Additionally, we explore the reasons why SOA predictions change with resolution throughout North America. It was found for the three commonly used resolutions for the GEOS-Chem model, $4^{\circ} \times 5^{\circ}, 2^{\circ} \times 2.5^{\circ}$ and $0.5^{\circ} \times 0.667^{\circ}$, the accuracy of SOA predictions, compared to the WACS 2010 campaign, was much higher at the higher resolutions of $2^{\circ} \times 2.5^{\circ}$ and $0.5^{\circ} \times 0.667^{\circ}$ than the comparison at the $4^{\circ} \times 5^{\circ}$ resolution . The particular enhancements between resolutions at Whistler were partially affected by the fact that Whistler lies within a coastal grid box at the $4^{\circ} \times 5^{\circ}$ resolutions.

It was found that the spatial resolution of the model greatly affected the predicted SOA concentrations across all of North America. The average SOA concentrations for the month of July, 2010 were found to be $32 \%$ higher in the $0.5^{\circ} \times 0.667^{\circ}$ simulation than the $4^{\circ} \times 5^{\circ}$ simulation. A similar but less significant trend was found between the $0.5^{\circ} \times 0.667^{\circ}$ and $2^{\circ} \times 2.5^{\circ}$ with a domain average difference of $19 \%$. The average concentrations for January, 2010 were found to be $23 \%$ higher in the $0.5^{\circ} \times 0.667^{\circ}$ simulation than the $4^{\circ} \times 5^{\circ}$ simulation and $8 \%$ higher between the $0.5^{\circ} \times 0.667^{\circ}$ and $2^{\circ} \times 2.5^{\circ}$ simulations. This difference was further investigated by comparing SOM concentrations across the same domain, where total emissions of SOM as well as the fraction of SOM that is SOA was found to increase at higher resolution. The increase in the partitioning of SOM to the aerosol phase was largely caused by higher-resolution simulations resolving hotspots of organic matter, which drives SOM to the aerosol phase (similar to what was shown in Stroud et al., 2011). The increases in organic hotspots more than compensates for the reduced amount of SOA in cold spot regions. Thus, the spatially averaged amount of SOA increases with resolution. The increased partitioning of SOM to the aerosol phase drives the overall increase in SOM at higher resolutions. This change is also driven by lifetime differences between secondary organic gases and SOA due to differences in dry deposition lifetimes in GEOS-Chem.

The results in this paper suggest that there is a significant dependence of SOA concentrations on model resolution when traditional biogenic SOA schemes with partitioning are used. Coarse grid resolution simulations may partially contribute to the traditional under-prediction of SOA in models (e.g. Heald et al., 2005; Volkamer et al., 2006). However, as only traditional gas-phase SOA mechanisms were tested in this paper, it is unclear how the resolution dependence of SOA will change due to recent developments in multi-generational secondary-organic chemistry, aqueousphase SOA formation, the formation of very-low volatility SOA and/or mass-transfer limitations due to highly vis- cous aerosols. In particular, the inclusion of semi-volatile primary organic aerosol (POA) (e.g. Robinson et al., 2007) could intensify this hotspot effect as this semi-volatile POA would have high partitioning ratios near large anthropogenic sources. However, it is important that the effects of grid resolution of SOA predictions be tested regardless of SOA scheme.

Acknowledgements. Funding for the Whistler Aerosol and Cloud Study 2010 was provided through the Clean Air Regulatory Agenda (CARA) through Environment Canada. Funding for CDW and JRP was provided through Environment Canada's Grants and Contribution program (G\&C 1004966). Many thanks to cooperation and support from Whistler-Blackcomb and associated staff.

Edited by: D. Spracklen

\section{References}

Albrecht, B.: Aerosols, cloud microphysics, and fractional cloudiness, Science, 245, 1227-1230, 1989.

Barkley, M. P., Palmer, P., Ganzeveld, L., Arneth, A., Hagberg, D., Karl, T., Guenther, A., Paulot, F., Wennber, P. O., Mao, J., Kurosu, T. P., Chance, K., Muller, J-F., De Smedt, I., Roozendael, M. V., Chen, D., Wang, Y. and Yantosca, R. M.: Can a "state of the art" chemistry transport model simulate Amazonian tropospheric chemistry?, J. Geophys. Res., 116, D16302, doi:10.1029/2011JD015893, 2011

Brock, C. A., Murphy D. M., Bahreini R., and Middlebrook A. M.: Formation and growth of organic aerosols downwind of the Deepwater Horizon oil spill, Geophys. Res. Let., 38, L17805, doi:10.1029/2011GL048541, 2011.

Cappa, C. D. and Jimenez, J. L.: Quantitative estimates of the volatility of ambient organic aerosol, Atmos. Chem. Phys., 10, 5409-5424, doi:10.5194/acp-10-5409-2010, 2010.

Carlton, A.G., Bhave, P. V., Napelenok, S., Edney, E. O., Sarwar, G., Pinder, R. W., Pouliot, G., and Houyoux, M.: Treatment of Secondary Organic Aerosol in CMAQv4.7, Environ. Sci. Technol, 22, 8553-8560, doi:10.1021/es100636q, 2010.

Chung, S. H. and Seinfeld, J. H.: Global distribution and climate forcing of carbonaceous aerosols, Geophys. Res. Lett., 107, 4407, doi:10.1029/2001JD001397, 2002.

Ervens, B., Carlton, A. G., Turpin, B. J., Altieri, K. E., Kreidenweis, S. M., and Feingold, G.: Secondary organic aerosol yields from cloud-processing of isoprene oxidation products, Geophys. Res. Lett., 35, L02816, doi:10.1029/2007GL031828, 2008.

Goldstein, A. and Galbally, I.: Known and unexplored organic constituents in the earth's atmosphere, Environ. Sci. Technol., 41, 1514-1521, 2007.

Guenther, A., Karl, T., Harley, P., Wiedinmyer, C., Palmer, P. I., and Geron, C.: Estimates of global terrestrial isoprene emissions using MEGAN (Model of Emissions of Gases and Aerosols from Nature), Atmos. Chem. Phys., 6, 3181-3210, doi:10.5194/acp-63181-2006, 2006.

Hand, J. L., Schichtel, B. A., Pitchford, M., Malm, W. C., and Frank, N. H.: Seasonal composition of remote and urban fine particu- 
late matter in the United States, J. Geophys. Res., 117, D05209, doi:10.1029/2011JD017122, 2012.

Heald, C.L., Jacob, D. J., Park, R. J., Russell, L. M., Huebert, B. J., Seinfeld, J. H., Liao, H., and Weber, R. J.: A large organic aerosol source in the free troposphere missing from current models, Geophys. Res. Lett., 32, L18809, doi:10.1029/2005GL023831, 2005.

Henze, D. K. and Seinfeld, J. H.: Global secondary organic aerosol from isoprene oxidation, Geophys. Res. Lett., 33, L09812, doi:10.1029/2006GL025976, 2006.

Henze, D. K., Seinfeld, J. H., Ng, N. L., Kroll, J. H., Fu, T.-M., Jacob, D. J., and Heald, C. L.: Global modeling of secondary organic aerosol formation from aromatic hydrocarbons: highvs. low-yield pathways, Atmos. Chem. Phys., 8, 2405-2420, doi:10.5194/acp-8-2405-2008, 2008.

Intergovernmental Panel on Climate Change: Climate Change 2007 - The Physical Science Basis: Contribution of Working Group I to the Fourth Assessment Report of the IPCC, Cambridge University press, 2007.

Jang, M. S., Czoschke, N. M., Lee, S., and Kamens, R. M.: Heterogeneous atmospheric aerosol production by acidcatalyzed particle-phase reactions, Science, 298, 814-817, doi:10.1126/science.1075798, 2002.

Jimenez, J. L., Canagaratna, M. R., Donahue, N. M., Prevot, A.S, Zhang, Q., Kroll, J. H., DeCarlo, P. F., Allan, J. D., Coe, H., Ng, N. L., Aiken, A. C., Docherty, K. S., Ulbrich, I. M., Grieshop, A. P., Robinson, A. L., Duplissy, J., Smith, J. D., Wilson, K. R., Lanz, V. A., Hueglin, C., Sun, Y. L., Tian, J., Laaksonen, A., Raatikainen, T., Rautiainen, J., Vaattovaara, P., Ehn, M., Kulmala, M., Tomlinson, J. M., Collins, D. R., Cubison, M. J., Dunlea, E. J., Huffman, J. A., Onasch, T. B., Alfarra, M. R., Williams, P. I., Bower, K., Kondo, Y., Schneider, J., Drewnick, F., Borrmann, S., Weimer, S., Demerjian, K., Salcedo, D., Cottrell, L., Griffin, R., Takami, A., Miyoshi, T., Hatakeyama, S., Shimono, A., Sun, J. Y., Zhang, Y. M., Dzepina, K., Kimmel, J. R., Sueper, D., Jayne, J. T., Herndon, S. C., Trimborn, A. M., Williams, L. R., Wood, E. C., Middlebrook, A. M., Kolb, C. E., Baltensperger, U., and Worsnop, D. R.: Evolution of Organic Aerosols in the Atmosphere, Science, 326, 1525-1529, 2009.

Kanakidou, M., Seinfeld, J. H., Pandis, S. N., Barnes, I., Dentener, F. J., Facchini, M. C., Van Dingenen, R., Ervens, B., Nenes, A., Nielsen, C. J., Swietlicki, E., Putaud, J. P., Balkanski, Y., Fuzzi, S., Horth, J., Moortgat, G. K., Winterhalter, R., Myhre, C. E. L., Tsigaridis, K., Vignati, E., Stephanou, E. G., and Wilson, J.: Organic aerosol and global climate modelling: a review, Atmos. Chem. Phys., 5, 1053-1123, doi:10.5194/acp-5-1053-2005, 2005.

Kim, Y., Sartelet, K., and Seigneur, C.: Formation of secondary aerosols over Europe: comparison of two gas-phase chemical mechanisms, Atmos. Chem. Phys., 11, 583-598, doi:10.5194/acp-11-583-2011, 2011.

Lane, T.E., Donahue, N., and Pandis, S.: Simulating secondary organic aerosol formation using the volatility basis-set approach in a chemical transport model, Atmos. Environ., 32, 7439-7451, 2008.

Leaitch, R., Macdonald, A. M., Brickell, P. C., Liggio, J., Sjostedt, S. J., Vlasenko, A., Bottenheim, J. W., Huang, L., Li, S., Liu, P. S.K., Toom-Sauntry, D., Hayden, K. A., Sharma, S., Shantz, N. C., Wiebe, A., Zhang, W., Abbatt, J., Slowik, J. G., Chang, R. Y.-W., Russell, L. M., Schwartz, R. E., Takahama, S., Jayne, J.
T., and Ng, N. L.: Temperature response of the submicron organic aerosol from temperate forests, Atmos. Environ., 37, 6696-6704, 2010.

Lin, G., Penner, J. E., Sillman, S., Taraborrelli, D., and Lelieveld, J.: Global modeling of SOA formation from dicarbonyls, epoxides, organic nitrates and peroxides, Atmos. Chem. Phys., 12, 47434774, doi:10.5194/acp-12-4743-2012, 2012.

Macdonald, A. M., Leaitch, W. R., Abbatt, J. P. D., Ahlm, L., AlBasheer, W., Betram, A., Buller, J., Campuzano-Jost, P., Chan, E., Corbin, J., Cziczo, D., Elford, A., Hayden, K. A., Herckes, P., Lee, A. K. Y., Li, S.-M., Liggio, J., Liu, P. S. K., Mihele, C., Noone K., Pierce, J. R., Russell, L. M., Toom-Sauntry, D., Schroder, J., Sharma, S., Sheppard, A., Sjostedt, S. J., Slowik, J. G., Strawbridge, K., Stupple, G., Vlasenko, A., Wainwright, C., Wang, Y., Wentzell, J., Wiebe, H. A., and Wong, J. P. S.: Overview of the 2010 Whistler Aerosol and Cloud Study, in preparation, 2012.

Odum, J. R., Jungkaamp, T. P. W., Griffin, R. J., Flagan, R. C., and Seinfeld, J. H.: The Atmospheric Aerosol-Forming Potential of Whole Gasoline Vapor, Science, 276, 5309, 96-99, doi: 10.1126/science.276.5309.96, 1997.

Pankow, J. F.: An absorption model of gas/particle partitioning of organic compounds in the atmosphere, Atmos. Environ., 28A, 185-188, 1994.

Petters, M. D. and Kreidenweis, S. M.: A single parameter representation of hygroscopic growth and cloud condensation nucleus activity, Atmos. Chem. Phys., 7, 1961-1971, doi:10.5194/acp-71961-2007, 2007.

Pierce, J. R. and Adams, P. J.: Uncertainty in global CCN concentrations from uncertain aerosol nucleation and primary emission rates, Atmos. Chem. Phys., 9, 1339-1356, doi:10.5194/acp-91339-2009, 2009.

Pierce, J. R., Riipinen, I., Kulmala, M., Ehn, M., Petäjä, T., Junninen, H., Worsnop, D. R., and Donahue, N. M.: Quantification of the volatility of secondary organic compounds in ultrafine particles during nucleation events, Atmos. Chem. Phys., 11, 90199036, doi:10.5194/acp-11-9019-2011, 2011.

Pierce, J. R., Leaitch, W. R., Liggio, J., Westervelt, D. M., Wainwright, C. D., Abbatt, J. P. D., Ahlm, L., Al-Basheer, W., Cziczo, D. J., Hayden, K. L., Lee, A. K. Y., Li, S.-M., Russell, L. M., Sjostedt, S. J., Strawbridge, K. B., Travis, M., Vlasenko, A., Wentzell, J. J. B., Wiebe, H. A., Wong, J. P. S., and Macdonald, A. M.: Nucleation and condensational growth to $\mathrm{CCN}$ sizes during a sustained pristine biogenic SOA event in a forested mountain valley, Atmos. Chem. Phys., 12, 3147-3163, doi:10.5194/acp-12-3147-2012, 2012.

Robinson, A. L., Donahue, N. M., Shrivastava, M. K., Weitkamp, E. A., Sage, A. M., Grieshop, A. P., Lane, T. E., Pierce, J. R., and Pandis, S. N: Rethinking organic aerosols: Semivolatile emissions and photochemical aging, Science, 315, 1259-1262, 2007.

Riipinen, I., Pierce, J. R., Yli-Juuti, T., Nieminen, T., Häkkinen, S., Ehn, M., Junninen, H., Lehtipalo, K., Petäjä, T., Slowik, J., Chang, R., Shantz, N. C., Abbatt, J., Leaitch, W. R., Kerminen, V.-M., Worsnop, D. R., Pandis, S. N., Donahue, N. M., and Kulmala, M.: Organic condensation: a vital link connecting aerosol formation to cloud condensation nuclei (CCN) concentrations, Atmos. Chem. Phys., 11, 3865-3878, doi:10.5194/acp-11-38652011, 2011. 
Shilling, J. E., Chen, Q., King, S. M., Rosenoern, T., Kroll, J. H., Worsnop, D. R., McKinney, K. A., and Martin, S. T.: Particle mass yield in secondary organic aerosol formed by the dark ozonolysis of $\alpha$-pinene, Atmos. Chem. Phys., 8, 2073-2088, doi:10.5194/acp-8-2073-2008, 2008.

Shiraiwa, M., Ammann, M., Koop, T., and Pöschl, U.: Gas uptake and chemical aging of semisolid organic aerosol particles, P. Natl. Acad. Sci., 108, 11003-11008, 2011.

Spracklen, D. V., Jimenez, J. L., Carslaw, K. S., Worsnop, D. R., Evans, M. J., Mann, G. W., Zhang, Q., Canagaratna, M. R., Allan, J., Coe, H., McFiggans, G., Rap, A., and Forster, P.: Aerosol mass spectrometer constraint on the global secondary organic aerosol budget, Atmos. Chem. Phys., 11, 12109-12136, doi:10.5194/acp-11-12109-2011, 2011.

Stroud, C. A., Makar, P. A., Moran, M. D., Gong, W., Gong, S., Zhang, J., Hayden, K., Mihele, C., Brook, J. R., Abbatt, J. P. D., and Slowik, J. G.: Impact of model grid spacing on regionaland urban-scale air quality predictions of organic aerosol, Atmos. Chem. Phys., 11, 3107-3118, doi:10.5194/acp-11-31072011, 2011.

Twomey, S.: Pollution and the Planetary Albedo, Atmos. Environ., 8, 1251-6, doi:10.1016/0004-6981(74)90004-3, 1974.

Vaden T. D., Imre, D. G., Beranek, J., Shrivastava, M. K. B., and Zelenyuk, A.: Evaporation Kinetics and Phase of Laboratory and Ambient Secondary Organic Aerosol, P. Natl. Acad. Sci. USA, 108, 2190-2195, doi:10.1073/pnas.1013391108, 2010. van Donkelaar, A., Martin, R. V., Leaitch, W. R., Macdonald, A. M., Walker, T. W., Streets, D. G., Zhang, Q., Dunlea, E. J., Jimenez, J. L., Dibb, J. E., Huey, L. G., Weber, R., and Andreae, M. O.: Analysis of aircraft and satellite measurements from the Intercontinental Chemical Transport Experiment (INTEX-B) to quantify long-range transport of East Asian sulfur to Canada, Atmos. Chem. Phys., 8, 2999-3014, doi:10.5194/acp-8-2999-2008, 2008.

van Donkelaar, A.: Global estimates of ambient fine particulate matter concentrations from satellite-based aerosol optical depth: Development and application, Environ. Health. Perspec., 118, 847855, doi:10.1289/ehp.0901623, 2010.

Volkamer, R., Jimenez, J. L., Dzepina, K., Salcedo, D., SanMartini, F. M., Molina, L. T., Worsnop, D. R., and Molina, M. J.: Secondary Organic Aerosol formation from Anthropogenic Air Pollution: Rapid and higher than expected, Geophys. Res. Lett., 33, L17811, doi:10.1029/2006GL026899, 2006.

Weigum, N. M., Stier, P., Schwarz, J. P., Fahey, D. W., and Spackman, J. R.: Scales of variability of black carbon plumes over the Pacific Ocean, Geophys. Res. Lett., 39, L15804, doi:10.1029/2012GL052127, 2012. 